\title{
Toxicity Assessment of a Multicomponent Antiparasitic Drug in Animals
}

\author{
Irina A. Stepanova*, Mikhail V. Arisov and Gulnara B. Arisova \\ All-Russian Scientific Research Institute of Fundamental and Applied Parasitology of Animals and Plants named after K.I. Skryabin -Branch of the \\ Federal State Budget Scientific Institution «Federal Scientific Center-All-Russian Scientific Research Institute of Experimental Veterenari Medicina \\ K.I. Skryabin and Y.R. Kovalenko the RussianAcademy of Sciences», B. Cheremushkinskaya Street 28, 117218 Moscow, Russia \\ *Corresponding author's Email: irinkastepanova@yandex.ru; iDORCiD: 0000-0002-1316-398X
}

\begin{abstract}
The important aspect of the high quality new pharmaceuticals is safety assessment in animals in practical conditions. Toxicity assessment of the new antiparasitic multicomponent drug (Inspector Quadro Tabs) composed of lufenuron, praziquantel and moxidectin in the form of tablets for cats and dogs was carried out. The parameters of acute oral toxicity were determined on white mice and white rats and subchronic toxicity was observed after repeated oral administration to rats. Embryotoxicity and teratogenicity of the drug were also evaluated. As a result of toxicological studies, median lethal doses $\left(\mathrm{LD}_{50}\right)$ of the drug during oral administration to the 60 white mice were established which were equal to the following: $\mathrm{LD}_{50}=14800 \mathrm{mg} / \mathrm{kg}$ (Karber's method), $13800 \mathrm{mg} / \mathrm{kg}$ (Miller and Tatener's method); to the white rats $\mathrm{LD}_{50}>16912 \mathrm{mg} / \mathrm{kg}$; according to the generally accepted classification, the drug belongs to the fourth class of hazard (low hazard substances). It was established that doses of $1691 \mathrm{mg} / \mathrm{kg}, 846 \mathrm{mg} / \mathrm{kg}$ and $338 \mathrm{mg} / \mathrm{kg}$ were threshold in a subchronic experiment on the rats. Moreover, it was found that the drug did not possess embryotoxic and teratogenic properties in pregnant female rats. Experimental results have confirmed the low toxicity of a new antiparasitic multicomponent drug.
\end{abstract}

Key words: Acute toxicity, Antiparasitic Drug, Embryotoxicity, Mice, Rats, Subchronic Toxicity

\section{INTRODUCTION}

Nowadays, the urgent task of the modern veterinary science is a development of safe and effective antiparasitic drugs with a new combination of actual substances. The combined parasitic diseases of animals can be often found in veterinary practice so antiparasitic drugs should have several substances, which are active against different kinds of parasites (Arisov and Smirnova, 2016). However, besides the high efficiency, drugs should also be safe and have low toxicity level. Before carrying out clinical studies of the drug efficiency, preclinical trial is usually made, which cover studying of the toxicity of the drug in laboratory animals. Preclinical trials use standard methods of studying of the acute and subchronic toxicity and embryotoxicity of the drug in laboratory animals, according to guidelines for conducting preclinical studies of drugs (Mironov, 2012). For example, Nazarova (2014) and Polishuk et al. (2015) have used standard methods of studying toxicity for the determination of safety of the nanocrystal powders of metals which have been used as biologically active supplements for feeding animals.

Lutfullin et al. (2017) and Lutfullin et al. (2018) carried out studies on the toxicological parameters of the antiparasitic NB compound (in these authors' article it is presented only such a name of the drug as "NB compound", concealed data) on white mice and white rats, which included monitoring of hematological and biochemical blood parameters, pathoanatomical studies of animal corpses, fetuses, etc. One of the most dangerous effects of drugs is embryotoxic and teratogenic ones; therefore, studying the effects of drugs on the reproductive function of animals is an important task in veterinary medicine. Direct impact on the mother's body, the natural physiological barrier (placental barrier), and the direct effect on the fetus is possible when using the drugs. Embryotoxicity and fetotoxicity can occur in increased levels of embryonic mortality, changes in body weight, craniocaudal size of the fetus, delayed skeletal ossification, and an increase in perinatal pathology (Burkov, 2013).

\section{MATERIALS AND METHODS}

\section{Ethical approval}

This study used the following methods to reduce the pain and suffering of the experimental animals. The most humane and sparing methods and procedures were used towards animals; the means to prevent pain and suffering at animals were also used. Any painful procedures with animals were carried out according to the guidelines and standards: 
European Convention for the Protection of Vertebrate Animals Used for Experimental and other Scientific Purposes (ETS 123). Strasbourg, 1986. Directive of the European Parliament and the Council of the EU 2010/63/EU of September 22, 2010 on the protection of animals used for scientific research. When carrying out the operations with the animals, we also used the guide for the care and use of laboratory animals National Academy press (Washington, USA).

\section{Experimental groups}

Sixty white male mice, 84 white male rats, 42 white female rats were held in the vivarium of All-Russian Research Institute of Fundamental and Applied Parasitology of Animals and Plants, a branch of the Federal State Budgetary Scientific Institution, Federal Research Center - All-Russian Scientific Research Institute of Experimental Veterinary Medicine. The animals were randomized into groups and did not take part in any studies before, 6 groups of 10 mice and 4 groups of 6 rats were formed to study the parameters of acute oral toxicity of the drug, 4 groups of 10 animals were formed to study subchronic toxicity in rats, 62 rats were used to study the embryotoxicity of the drug which were divided into 7 experimental groups of 6 female rats and 20 male rats in each group. Feeding was carried out ad libitum with complete extruded feed for laboratory animals and access to water was free. The temperature and humidity in the vivarium were constantly monitored (Air temperature: $18-22{ }^{\circ} \mathrm{C}$; relative humidity: $50-65 \%$ ). To study the parameters of acute oral toxicity of the drug in mice, five experimental and one control groups of white male mice weighing 19-22 $\mathrm{g}$ were formed which each group contained 10 individuals. To study the acute oral toxicity of the drug in rats, 3 experimental and 1 control groups of white outbred male rats weighing 185-210 g were formed, in which group there were 6 individuals. Subchronic toxicity was studied in 40 male rats with an initial mass of 165-200 g; they were divided into 3 experimental and 1 control groups with 10 animals in each group. The embryotoxicity of the test drug with repeated administration was studied on 42 white female rats weighing 200-220 g. For fertilization of the females, 20 males weighing 250-335 g (contained separately) were used. All females were divided into 7 experimental groups, with 6 individuals in each group. Males were placed for a night to females in the estrus and proestrus stages in a 4:1 ratio. The day of sperm detection in the vagina of females after placing males was counted as the first day of pregnancy (Figure 1).

\section{Determination of toxicological parameters of the drug in laboratory animals}

For this purpose, the drug was tested in mice in dose of 20000, 16800, 13600, 10400 and $6400 \mathrm{mg} / \mathrm{kg}$. For ease of administration, the drug in the amount of $20.0 \mathrm{~g}$ was crushed, diluted in $15 \mathrm{ml}$ of water, thoroughly mixed in a porcelain bowl with a pestle and the volume of the resulting suspension became $25.0 \mathrm{ml}$. Then this suspension was administered into fast mice once through intragastric probe with dose of $0.25 ; 0.21 ; 0.17 ; 0.13$ and $0.08 \mathrm{ml}$ per $10 \mathrm{~g}$ of animal mass, respectively. The control animals were given only drinking water in the amount of $0.25 \mathrm{ml}$ per $10 \mathrm{~g}$ body mass. Dose of 10147,14882 and $16912 \mathrm{mg} / \mathrm{kg}$ of the drug was tested in rats. For ease of administration, the drug in the amount of $23 \mathrm{~g}$ was crushed, diluted in $20 \mathrm{ml}$ of water, thoroughly mixed in a porcelain bowl with a pestle and the volume of the resulting suspension became $34.0 \mathrm{ml}$. Then this suspension was administered into fast rats once with guide of an intragastric probe in doses of $1.5 ; 2.2$ and $2.5 \mathrm{ml}$ per $100 \mathrm{~g}$ of animal weight, respectively. The control animals were given only drinking water in the amount of $2.5 \mathrm{ml}$ per $100 \mathrm{~g}$ body mass. The general condition and behavior of the animals, the occurrence of intoxication symptoms, and the possible deaths on days 1, 3, 7, 9, and 14 were monitored within 14 days.

\section{Determination of subchronic toxicity in laboratory animals}

The tested drug was administered intragastrically on daily basis in 14 days. The doses of $1691,846 \mathrm{and} 338 \mathrm{mg} / \mathrm{kg}$ $(1 / 10,1 / 20$, and $1 / 50$ of maximum possible for the administration into a stomach) were tested in rats. For ease of administration, $8.0 \mathrm{~g}$ of the drug was diluted in $30 \mathrm{ml}$ of water, mixed thoroughly, and $34 \mathrm{ml}$ of suspension was obtained. Then this suspension was administered using an intragastric probe in doses of $0.72 ; 0.36$ and $0.14 \mathrm{ml}$ per $100 \mathrm{~g}$ of animal weight, which corresponds to dose of 1691, 846 and $338 \mathrm{mg} / \mathrm{kg}$. The control animals were given only drinking water in the amount of $0.72 \mathrm{ml}$ per $100 \mathrm{~g}$. During the entire period of use of the drug, the general condition and behavior of the animals, reactions to stimuli (sound, light), symptoms of intoxication, and possible death were observed. On the first day after the last administration of the drug $\left(15^{\text {th }}\right.$ day of the experiment), half of the animals from each group were euthanized and blood samples were taken to determine hematological and biochemical parameters. Ten days after the last administration ( $24^{\text {th }}$ day of the experiment) the second half of the animals were euthanized and blood samples were taken to assess the degree of reversibility of possible toxic processes after repeated use of the drug. Blood samples were taken, organ samples were taken from all rats in each group, the mass of the organs was determined, and the mass coefficients were calculated. The functional state of the central nervous system was assessed by visual observations of motor activity and reactions to external stimuli. 


\section{Equipments}

The main indicators of rat peripheral blood were determined on a PCE 90-vet hematology analyzer (ERMA INC, Japan). When calculating leukocyte formula, blood smears were stained according to the Romanovsky-Giems method using a set for fixing and staining for hematological and cytological studies Haemocrafix (Russia). Stained smears were examined under a light microscope (Levenhuk D670T, USA). Blood biochemical parameters were determined on a Biosystems A-15 analyzer (Spain). Macroscopic examination of organs (liver, lungs, kidneys, heart, spleen, stomach and intestines) were carried out.

\section{Determination of drug embryotoxicity}

The tested drug was administered to pregnant female rats in 1,2 and 3 experimental groups in a form of suspension in $1 \%$ starch gel in therapeutic dose, and also female rats in 4, 5 and 6 groups received drug and doubled therapeutic dose according to Mironov (2012), (20 mg of lufenuron, $10 \mathrm{mg}$ of praziquantel, and 0.6 of moxidectin per $1 \mathrm{~kg}$ of the animal's weight) orally during the critical period of embryogenesis (1-6, 6-16 and 16-19 days of pregnancy). The therapeutic dose of the drug divided by the actual substances which were $10 \mathrm{mg}$ of lufenuron, $5 \mathrm{mg}$ of praziquantel, and $0.3 \mathrm{mg}$ of moxidectin per $1 \mathrm{~kg}$ of the animal's weight. To prepare the suspension, $120 \mathrm{mg}$ of the drug were crushed in a porcelain bowl with a pestle and mixed with $10.0 \mathrm{ml}$ of $1 \%$ starch gel. The resulting suspension was administered to rats of the experimental groups in doses of $0.5 \mathrm{ml} / 100 \mathrm{~g}$ (First, second and third groups) and $1.0 \mathrm{ml} / 100 \mathrm{~g}$ (Fourth, fifth and sixth groups). The control group of pregnant females received a solution of $1 \%$ starch paste without the drug. On the 20th day of embryogenesis, all pregnant animals were killed by the method of decapitation. At necropsy the uterus and ovaries of female rats were removed (Figure 2).

In the ovaries, the number of corpus luteums (CLs) of pregnancy was counted. The implantation sites, live, dead, and resorbed fetuses were also counted in the uterus. Fetuses were examined under a binocular magnifying glass to detect external anomalies, then they were weighed and the size of the embryo was measured, along with the mass and the diameter of the placenta. The ratio of the number of CLs, implantation sites and live fetuses was used to calculate indicators of total embryonic mortality, pre-implantation and post-implantation death. After weighing, the fetuses in the litter from each female were divided into two equal parts. To study the skeletal system according to the Dawson method, half of the fetuses were left in 95\% ethanol for 7-10 days, the alcohol was changed periodically. Then the embryo was immersed in a $1 \% \mathrm{KOH}$ solution for clearing soft tissue. After 2-3 days (when the bone marks were visible), the fetuses were taken out of alkali, washed with water and transferred to a solution consisting of $150 \mathrm{ml}$ of glycerol, $800 \mathrm{ml}$ of distilled water and $10 \mathrm{~g}$ of $\mathrm{KOH}$, as well as a few drops of $1 \%$ alizarin red solution. After 3-5 days, the ossified areas of the skeleton were painted in intense red-violet color. For bleaching of soft tissues and final enlightenment, the fetuses were transferred to a solution of glycerin, distilled water and $\mathrm{KOH}$ in the same ratios, but without the addition of a $1 \%$ solution of alizarin red. Then the fetuses were dehydrated by slow processing them through a mixture of alcohol, glycerin and water in different proportions $(1: 2: 7 ; 2: 2: 6 ; 4: 4: 2)$, equal parts of alcohol and glycerin, pure glycerin with 1-2 drops of formalin. The length of the centers of ossification of the skeleton of the stained embryo (scapular, brachial, ulnar, radial, femoral, large and small tibialis) was measured under a stereoscopic binocular microscope magnifier using an ocular micrometer (Figure 3). The remaining fetuses were put into Bowen's fluid for 14 days for microanatomical analysis for the presence of abnormalities of internal organs according to the Wilson method modified by Andrey Pavlovich Dyban (Dyban, 1986). According to the scheme, 8 transverse sections were made with the razor blade (Figure 4); all sections were analyzed under a MBS-2 stereomicroscope for the presence of internal anomalies in the fetuses. First, the head was removed from the body with the parallel cut to the lower jaw bone; then the series of cuts were performed: perpendicular to the lower jaw directly behind the vibrissae (condition of the lower jaw, anterior part of the hard palate and nasal cavity); through the middle of the eyeballs and olfactory bulbs; through the large lateral cranial diameter (the state of the brain: the cerebral cortex, lateral, third and fourth ventricles); parallel to the third cut (for the study of the cerebellum and the medulla oblongata). In front of the front legs - the neck is cut off from the body (esophagus, trachea, spinal cord, large vessels); directly behind the forelimbs through the organs of the chest (heart, lungs, bronchi, esophagus, spinal cord); midway between the seventh incision and the umbilical ring (the study of the liver and the state of the diaphragm); below the umbilical ring (intestine, pancreas, kidneys, ureters, bladder, rectum, genitals).

Embryo death at the pre and post-implantation stages of development (embryonic effect), the presence of abnormal development of the internal organs and skeleton (teratogenic effect), fertility, mass and length of fetuses, diameter and mass of the placenta, anogenital distance and the anogenital index, the length and number of bone ossification points in the fetuses of rats were assessment criteria of embryotoxic and teratogenic effects of the drug. 


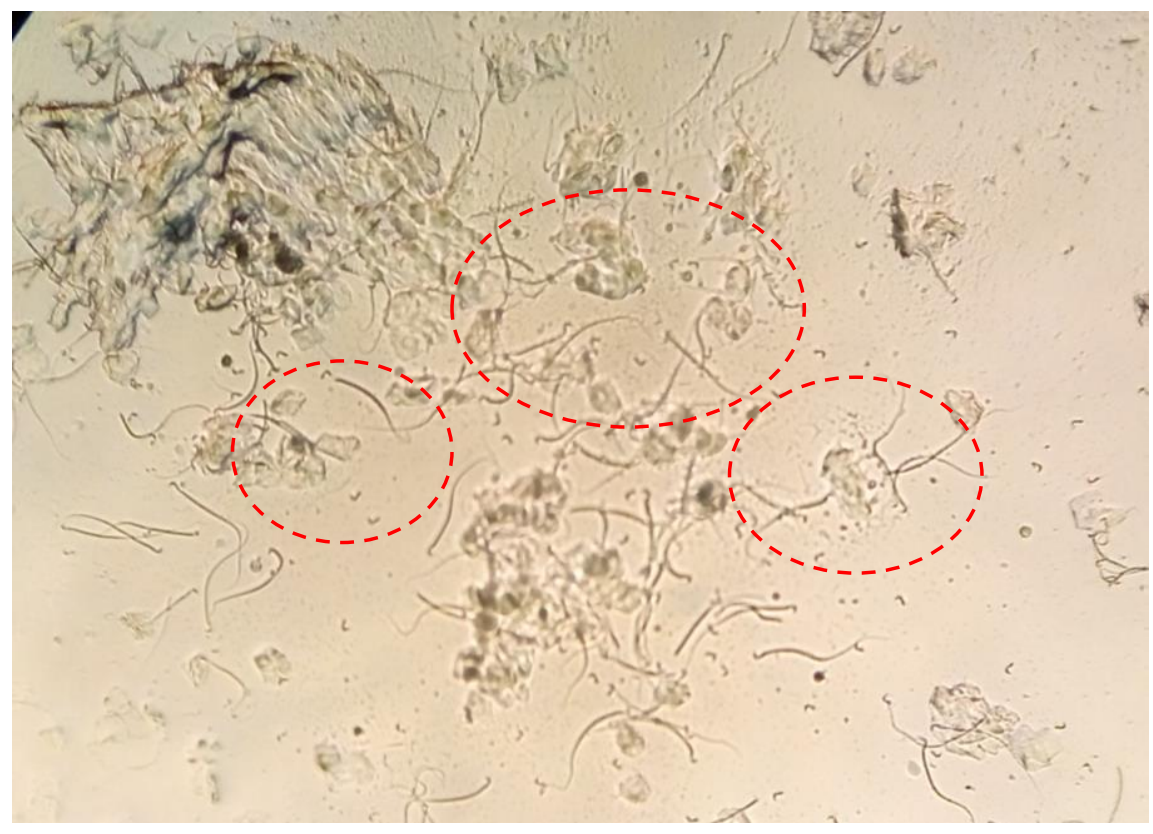

Figure1. Sperm cells detected in a vaginal smear of the female rat of the second experimental group during embryotoxic studies of the drug after her fertilization. Thin filaments are circled in red. The microscope Levenhuk D670T (USA), the magnification $\mathrm{x} 100$.

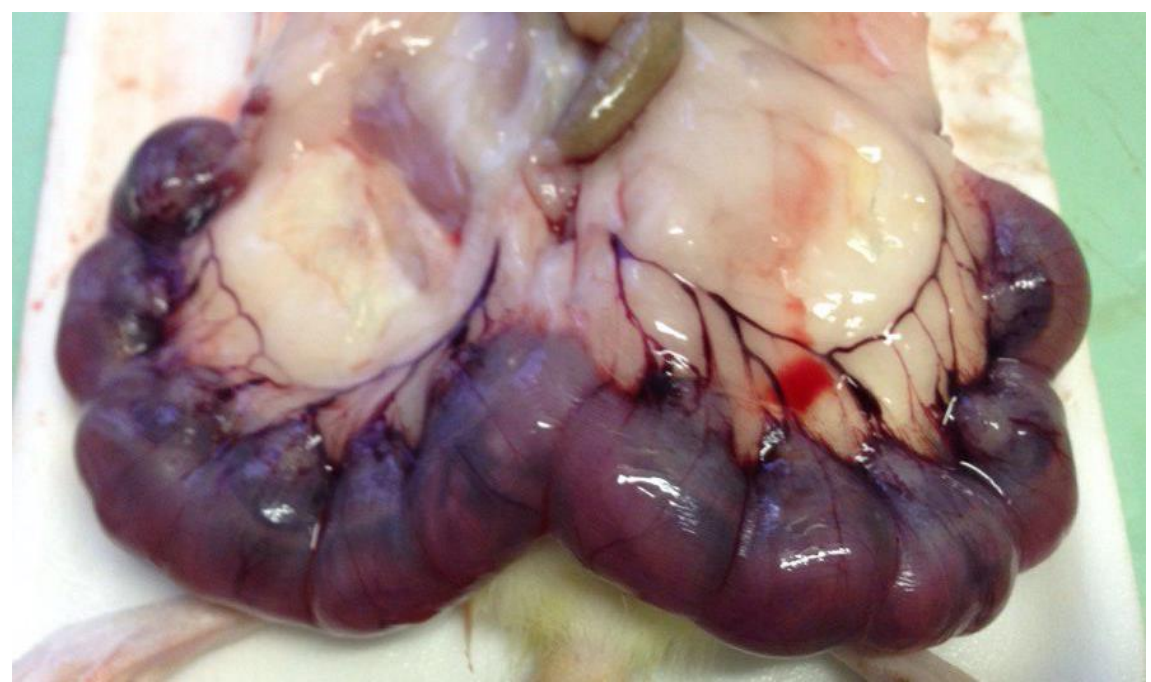

Figure 2. Dissection of the female rat with the extraction of the uterus (the female rat of the third experimental group during embryotoxic studies of the drug)

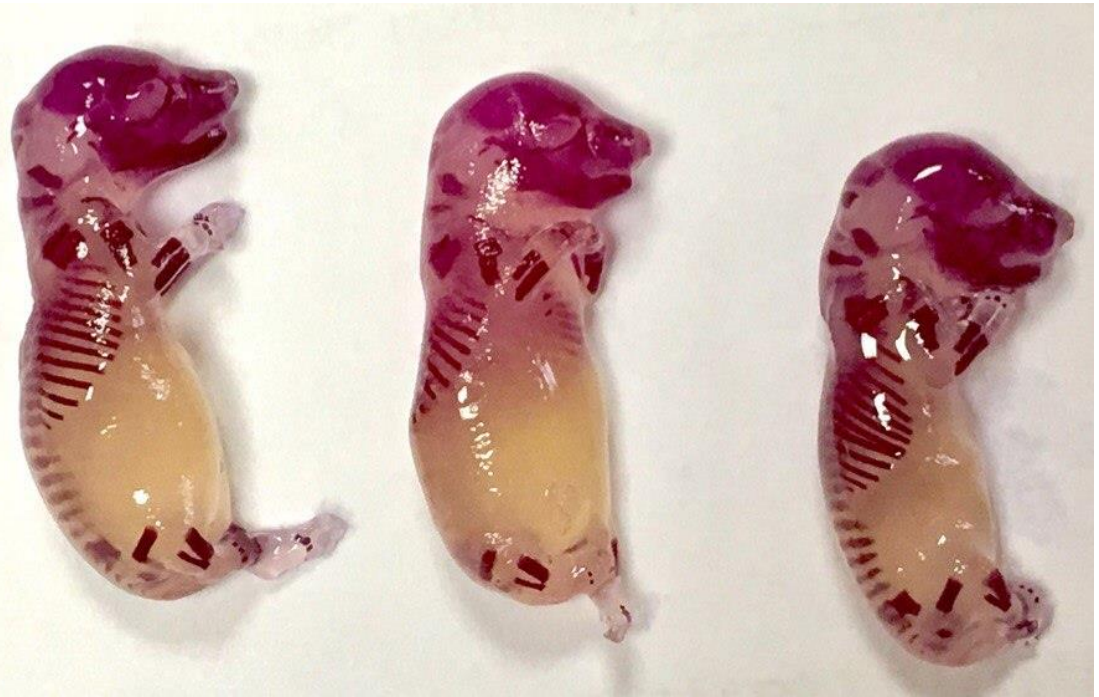

Figure 3. Fetuses of rats colored according to the Dawson's method. Ossified areas of the skeleton are painted red-violet, soft tissues are discolored. 


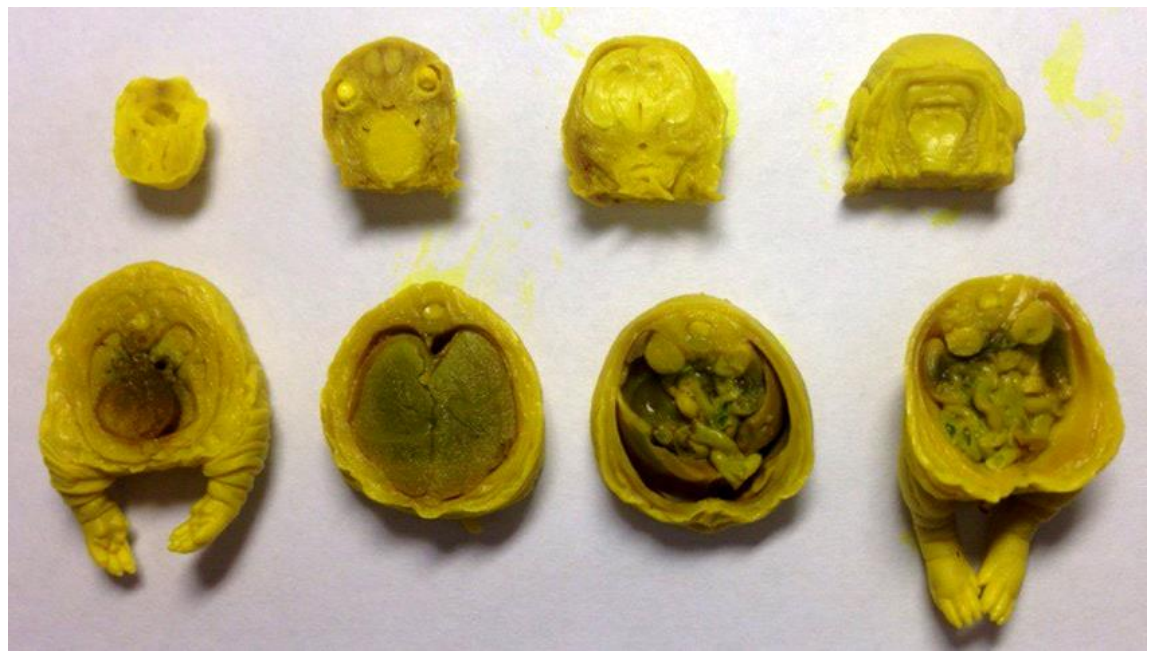

Figure 4. Transverse cuts of fetuses of rats (Wilson's method, modified by A.P. Dyban)

\section{RESULTS}

\section{Study of the acute oral toxicity in laboratory animals}

During the observation of the laboratory animals, the dependence of the ratio of dead animals to the volume of the administered dose was observed. After the administration of the dose of 20000, 16800, and $13600 \mathrm{mg} / \mathrm{kg}$, animals become despondent and anorexic and took lateral position before the death. During the autopsy, hyperemia of the gastric and intestinal mucous membrane and also swelling were revealed. The generalized results of the experiment to determine acute toxicity in mice are presented in table 1 .

The most toxic dose was $20000 \mathrm{mg} / \mathrm{kg}$ in the 1 st experimental group in which all the animals of the group was died. The dose of $16800 \mathrm{mg} / \mathrm{kg}$ was found to be less toxic in the 2nd experimental group in which the mortality of $60 \%$ of animals was noted. The indicators of the percentage of the increase in live weight in mice of the $2 \mathrm{nd}$ and $3 \mathrm{rd}$ experimental groups were statistically significantly lower than in the control group: $10.39 \pm 8.95 \%$ versus $28.23 \pm 4.92 \%$ and $7.40 \pm 9.82 \%$ versus $28,23 \pm 4.92 \%$, respectively. Indicators of the percentage of live weight gain of mice in the 4th and 5th experimental groups did not undergo significant changes compared to the same indicator in the control group.

Mice of the fifth experimental group which received the drug at a dose of $6400 \mathrm{mg} / \mathrm{kg}$ showed no statistically significant difference in live weight, the behavior and general condition did not differ from control animals. Based on the obtained data, the LD50 was calculated by the Karber's method as well as by the Miller- Tainter methods (Mironov, 2012).

$\mathrm{LD}_{50}=\mathrm{LD}_{100}-\frac{\sum(\mathrm{zxd})}{\mathrm{n}}$

$\mathrm{LD}_{100}$ : Dose caused death of all animals;

$\mathrm{z}$ : The arithmetic average of the number of animals which death was observed under the influence of two adjacent doses;

$d:$ :Interval between two adjacent doses;

$\mathrm{n}:$ Number of animals in a group.

$\mathrm{LD}_{50}$ of the drug (Inspector Quadro Tabs) in oral administration to mice, count according to the Karber's method, was equal to $14,800 \mathrm{mg} / \mathrm{kg}$ of the weight of the animal. In order to have a complete understanding of the $\mathrm{LD}_{50}$, which can vary depending on the individual characteristics of animals of a given species and age, it is necessary to know the amplitude of its variation. To calculate the confidence interval of the general average $\mathrm{LD}_{50}$ used the following formula:

Confidence interval of the general average $=\mathrm{LD}_{50} \pm \mathrm{t} * \mathrm{SLD}_{50}$

$\mathrm{LD}_{50}$ : Lethal dose, counted according to the diagram; t: Test of validity; $\mathrm{S} \mathrm{LD}_{50}$ : Error index $\mathrm{LD}_{50}$; Confidence interval of the general average $=13,800 \pm 2,340.9 \mathrm{mg} / \mathrm{kg}$

Thus, $\mathrm{LD}_{50}$ counted according to the Miller and Tatener's method is in the range between $11459.1 \mathrm{mg} / \mathrm{kg}$ and $16140.9 \mathrm{mg} / \mathrm{kg}\left(\mathrm{LD}_{50}=13800(11459.1 \div 16140.9) \mathrm{mg} / \mathrm{kg}\right)$. Therefore, taking into consideration $\mathrm{LD}_{50}$ counted by two methods and according to the common hygienic classification (GOST 12.1.007), drug (Inspector Quadro Tabs) belongs to the fourth class of hazard (low hazard substances). During the study of acute oral toxicity in rats, the general condition of the animals of all experimental groups that received doses of 10147, 14882, and $16912 \mathrm{mg} / \mathrm{kg}$ was satisfactory throughout the experiment, there were no changes in the behavior of the rats, and their levels of appetite and thirst were normal. No disturbance of coordination of movements and convulsions were noted, the tone of skeletal muscles corresponded to the norm; response to tactile, pain, sound and light stimuli was adequate. The hair of the experimental animals was smooth, shiny, without alopecia; the integrity of the skin was not broken, there was no hyperemia; the color of the visible mucous membranes corresponded to the norm; the frequency and depth of respiratory movements and the 
rhythm of heart contractions were not changed. It should be noted that a dose of $16912 \mathrm{mg} / \mathrm{kg}$ is the maximum possible for a single oral administration to animals of this species and this dose did not lead to the death of animals. Thus, the $\mathrm{LD}_{50}$ of the (Inspector Quadro Tabs) drug exceeds the dose of $16912 \mathrm{mg} / \mathrm{kg}$, which means that this drug (Inspector Quadro Tabs) belongs to the 4th hazard class (low hazardous substances).

\section{Study of the subchronic toxicity}

As a result of clinical examination of animals during the experiment, no signs of intoxication were observed in rats of the experimental groups. The general condition of the animals remained satisfactory, changes in behavior were not observed, appetite and thirst were not changed, and physiological parameters corresponded to the norm. The weight of the rats of the experimental groups in all weighing periods was not statistically significantly different from those of control animals. The relative mass of organs is a simple, but very clear indicator of the toxic effects of drugs with their long-term use. The calculation of the relative mass of each organ was carried out according to the formula:

$\mathrm{S}=(\mathrm{m} / \mathrm{M}) * 100$

$\mathrm{S}$ : The relative mass of the body, $\mathrm{m}$ : The mass of the organ $(\mathrm{g}), \mathrm{M}$ : The body weight of the animal $(\mathrm{g})$.

The results of calculations of mass coefficients indicate that at doses of 1691,846 and $338 \mathrm{mg} / \mathrm{kg}$, the mass coefficients of all organs of animals on the first day after the last injection of the drug did not differ statistically significantly from those of the control group. Also, no significant differences were found in the rates of the mass coefficients of the organs of the experimental animals compared with the control group in 10 days after the last administration of the tested drug (Table 2).

According to the results of the macroscopic study of organs, differences between groups were not established, and therefore the data of rat necropsy is presented as average for all groups. During external examination of rats, no secretions from natural openings were found, the hair was shiny, there were no alopecia lesions, the teeth were preserved, the visible mucous membranes were pale pink, shiny, deformation or swelling of the extremities were not detected, the development of the external genitalia was in accordance with the physiological norm. Thoracic and abdominal cavities did not contain effusion, the position of the internal organs of the thoracic and abdominal cavities were anatomically correct, the parietal and visceral pleura and peritoneum were thin, shiny, and smooth. A macroscopic examination of the liver, lungs, kidneys, spleen, and heart after administration of the drug to rats at the three doses indicated that there were no changes in the structure, shape and size of the internal organs, the surfaces were smooth, shiny, of a consistent consistency and color without indurations. In all animals of all experimental groups on the 15th day of the experiment, the structure of the stomach corresponded to the norm, the thickness of the stomach wall was not changed, and there was no hyperemia. The mesenteric membranes and glands of rats were not changed, the vessels were not filled with blood, the mesenteric lymph nodes are not enlarged, the intestines contain a small amount of yellowish pasty mass, and the mucous membrane was not changed. During an autopsy performed on the 24th day of the experiment, there were no differences in the macroscopic structure of the organs of rats of the experimental groups in comparison with the control analogues.

An objective determination of toxic properties in the experiments also included the determination of hematological parameters of rats. At first and tenth day after the last administration of the drug to rats of the experimental groups, no statistically significant changes in blood parameters were detected compared with the control group. According to the results of determination of the biochemical parameters of blood serum after prolonged use of the drug (Inspector Quadro Tabs), the following was noted: on the 15th day of the experiment in rats of the first experimental group, an increase in the content of direct bilirubin was observed: $0.72 \pm 0.30 \mu \mathrm{mol} / 1$ versus $0.34 \pm 0.14 \mu \mathrm{mol} / \mathrm{l}$ in the control group (Table 3), which may indicate the hepatotoxic effect of the tested dose. In the rats of the other groups, there were no statistically significant differences in the biochemical indicators compared with the control. Summarizing all the results of the experiment, we can conclude that the doses of the drug (Inspector Quadro Tabs) of $1691 \mathrm{mg} / \mathrm{kg}, 846 \mathrm{mg} / \mathrm{kg}$ and 338 $\mathrm{mg} / \mathrm{kg}$ when administered orally for 14 days are threshold.

\section{Study of the embryotoxicity of the drug}

As a result of the study, it was found that the drug for veterinary use (Inspector Quadro Tabs) in therapeutic and double therapeutic doses when administered orally to pregnant rats does not affect the morphometric parameters of the fetuses of rats when administered during pregnancy and does not cause developmental abnormalities. The study of the status of pregnant rats in the dynamics did not reveal the symptoms of the general toxic effect of the drug, the behavior; the consumption of water and food by the animals of the experimental and control groups did not differ. The drug in the tested doses did not affect the number of corpus luteum in the ovaries, did not have an embryolethal action, and did not cause the preimplantation death of fetuses. In groups of rats treated with the drug, the number of fetuses did not differ from number in the control group. It was established that the drug does not change the parameters of growth and development of the fetuses; during the study of the fetuses of rats of the control and experimental groups, developmental 
anomalies were not observed. When studying the process of ossification of different parts of the skeleton of the fetuses of rats it was observed that the drug does not affect the length and number of points of ossification of large bones.

Table 1. The results of the experiment to determine the acute oral toxicity of the multicomponent antiparasitic drug in mice

\begin{tabular}{|c|c|c|c|c|c|}
\hline Group & Number of mice & Dose (mg/kg) & Dose (ml/10g) & Died & Survived \\
\hline 1 experimental & 10 & 20000 & 0.25 & 10 & 0 \\
\hline 2 experimental & 10 & 16800 & 0.21 & 6 & 4 \\
\hline 3 experimental & 10 & 13600 & 0.17 & 3 & 7 \\
\hline 4 experimental & 10 & 10400 & 0.13 & 2 & 8 \\
\hline 5 experimental & 10 & 6400 & 0.1 & 0 & 10 \\
\hline Control & 10 & $\mathrm{H}_{2} \mathrm{O}$ (fresh) & 0.25 & 0 & 10 \\
\hline
\end{tabular}

Table 2. Mass coefficient of rat organs at 10 days after the last administration of the multicomponent antiparasitic drug $(\mathrm{n}=5)$

\begin{tabular}{|c|c|c|c|c|}
\hline \multirow{2}{*}{ Organs } & \multirow{2}{*}{ Control } & \multicolumn{3}{|c|}{ Dose } \\
\hline & & $1691(\mathrm{mg} / \mathrm{kg})$ & $846(\mathrm{mg} / \mathrm{kg})$ & 338 (mg/kg) \\
\hline Liver & $4.42 \pm 0.96$ & $4.33 \pm 0.52$ & $4.04 \pm 0.38$ & $4.28 \pm 0.35$ \\
\hline Kidney & $0.69 \pm 0.14$ & $0.65 \pm 0.05$ & $0.63 \pm 0.04$ & $0.68 \pm 0.02$ \\
\hline Spleen & $0.25 \pm 0.06$ & $0.26 \pm 0.1$ & $0.25 \pm 0.06$ & $0.29 \pm 0.06$ \\
\hline Lungs & $0.61 \pm 0.03$ & $0.54 \pm 0.12$ & $0.57 \pm 0.08$ & $0.58 \pm 0.15$ \\
\hline Heart & $0.37 \pm 0.1$ & $0.33 \pm 0.03$ & $0.32 \pm 0.02$ & $0.37 \pm 0.07$ \\
\hline
\end{tabular}

Table 3. Biochemical parameters of blood serum of rats after 14 day of administration of the multicomponent antiparasitic drug $(\mathrm{n}=5)$

\begin{tabular}{lccccc}
\hline \multirow{2}{*}{ Parameters } & Unit & Control & \multicolumn{3}{c}{ Dose } \\
\cline { 5 - 6 } & & & $\mathbf{1 6 9 1}(\mathbf{m g} / \mathbf{k g})$ & $\mathbf{8 4 6}(\mathbf{m g} / \mathbf{k g})$ & $\mathbf{3 3 8}(\mathbf{m g} / \mathbf{k g})$ \\
\hline Total bilirubin & $\mu \mathrm{mol} / \mathrm{l}$ & $2.74 \pm 1.10$ & $2.10 \pm 0.69$ & $2.54 \pm 1.32$ & $3.44 \pm 0.48$ \\
Direct bilirubin & $\mu \mathrm{mol} / \mathrm{l}$ & $0.34 \pm 0.14$ & $0.72 \pm 0.30 *$ & $0.62 \pm 0.57$ & $0.68 \pm 0.56$ \\
Aspartate aminotransferase & $\mathrm{U} / \mathrm{l}$ & $155.20 \pm 32.34$ & $127.00 \pm 39.53$ & $135.00 \pm 37.87$ & $150.00 \pm 21.52$ \\
Alanine aminotransferase & $\mathrm{U} / \mathrm{l}$ & $52.60 \pm 3.12$ & $47.80 \pm 11.29$ & $46.20 \pm 14$ & $48.00 \pm 7.18$ \\
Urea & $\mu \mathrm{mol} / 1$ & $5.04 \pm 1.18$ & $4.54 \pm 0.84$ & $4.64 \pm 0.69$ & $4.26 \pm 0.69$ \\
Creatinine & $\mu \mathrm{mol} / 1$ & $39.80 \pm 2.83$ & $39.60 \pm 4.78$ & $42.60 \pm 5.59$ & $41.60 \pm 7.32$ \\
Total protein & $\Gamma / 1$ & $63.40 \pm 2.08$ & $65.40 \pm 5.38$ & $64.40 \pm 2.86$ & $62.40 \pm 1.88$ \\
Alkaline phosphatase & $\mathrm{U} / \mathrm{l}$ & $242.6 \pm 75.78$ & $258 \pm 84.55$ & $298.6 \pm 47.24$ & $266.8 \pm 76.28$ \\
Alpha Amylase, total & $\mathrm{U} / 1$ & $644 \pm 58.96$ & $691.6 \pm 41.04$ & $675.80 \pm 49.39$ & $621.2 \pm 152.71$ \\
Glucose & $\mu \mathrm{mol} / 1$ & $6.46 \pm 0.91$ & $5.80 \pm 0.69$ & $6.92 \pm 0.83$ & $6.18 \pm 0.51$ \\
Lactate dehydrogenase & $\mathrm{U} / 1$ & $1394.6 \pm 516.15$ & $1176.8 \pm 302.46$ & $1252.2 \pm 555.39$ & $961 \pm 264.49$ \\
\hline Note: $*$ P value $>0.05$ & & & & &
\end{tabular}

\section{DISCUSSION}

It is well known that some insectoacaricides may have undesirable side effects when administered to specific species, for example the administration of fipronil to the rabbits during treatment of the psoroptic scab (Elhawary et al., 2018). In turn, present toxicological studies of the multicomponent drug "Inspector Quadro Tabs" containing 3 antiparasitic components found the absence of a side effect as embryotoxicity in pregnant animal. During the process of studying the toxicological parameters of the drug (Lufenuron, moxidectin, praziquantel), experiments on the study of allergenic properties were carried out (Stepanova and Koshkarev, 2019). As a result of research, it was found that the drug, after a 20-day sensitization of guinea pigs with epicutaneous, nasal and conjunctival samples, does not cause a specific response of the body and does not possess allergenic properties. During the study of acute oral toxicity of the drug containing moxidectin and praziquantel, it was found that the drug belongs to the 4th hazard class, and its dose of 142 $\mathrm{mg} / \mathrm{kg}$ is inactive (Arisov and Smirnova, 2016). The studied multicomponent antiparasitic drug containing moxidectin, praziquantel and lufenuron is also a low-hazard substance. In the veterinary practice, there was a registered case in which 3 dogs were orally administered a topical preparation containing imidacloprid and moxidectin as active substances (See et al., 2009). All toxic effects were reversible and after 48 hours, all dogs were clinically healthy. Tamparon et al. (2015) proved that abamectin, belonging to the group of avermectins, has a high toxicity for aquatic invertebrates, which is observed with lytic activity of sea urchin spermatozoa. Insecticide interferes with fertilization, 
preventing gamete fusion. But it is known that the main difference between avermectins and milbemycins (moxidectin) is the presence of a disaccharide in the avermectins molecule, which is absent in milbemycins (Safiullin, 2006), which may explain their lower toxicity to animals. Numerous studies have also proved the low toxicity of praziquantel, which allows it to be used for therapeutic purposes (Zuskova et al., 2018; Sun et al., 2016), which is confirmed by our studies of a multi-component preparation with praziquantel content of $8-11 \%$. When studying the toxicity and efficacy of the drug with the content of lufenuron for the treatment of fish ectoparasites, it was found that there were no histological signs of acute and chronic toxicosis, as well as mortality of fish (Tang et al., 2019), which confirms the low toxicity of lufenuron when used in drug (Inspector Quadro Tabs) for animals. In the present study examining of the drug embryotoxicity at a therapeutic and double therapeutic dose $(20 \mathrm{mg}$ of lufenuron, $10 \mathrm{mg}$ of praziquantel, $0.6 \mathrm{mg}$ of moxidectin per $1 \mathrm{~kg}$ of body mass weight) by oral administration to the pregnant rats, showed that the drug has no effect on the morphometric parameters of the rat fetuses while administration in pregnancy period did not cause any abnormalities. The drug did not affect the number of CL in the ovaries in the tested doses, did not have an embryolethal effect and did not cause pre-implantation death of the embryos. The study of the toxicological parameters of the combination of actual substances lufenuron, moxidectin and praziquantel in the tablet form was carried out for the first time and the results showed that the drug belongs to the group of low-hazard substances, the drug is safe for use in clinical studies of therapeutic efficacy in parasitic diseases of the target animal species.

\section{CONCLUSION}

As a result of the study, acute oral toxicity of the drug (Inspector Quadro Tabs) was evaluated in white outbred rats and white outbred mice. It was determined that $\mathrm{LD}_{50}$ of the drug during single oral administration to the rats is more than $16912 \mathrm{mg} / \mathrm{kg}$. During a single oral administration of the drug to white outbred mice, $\mathrm{LD}_{50}$ calculated according to the Karber'a method was $14800 \mathrm{mg} / \mathrm{kg}$ of animal weight; The $\mathrm{LD}_{50}$ calculated by the Miller and Tainter's method was $13800(11459.1 \div 16140.9) \mathrm{mg} / \mathrm{kg}$. According to the generally accepted hygienic classification, the drug belongs to the fourth hazard class - low hazardous substances (GOST 12.1.007). In a subchronic experiment on rats, it was established that doses of $1691 \mathrm{mg} / \mathrm{kg}, 846 \mathrm{mg} / \mathrm{kg}$, and $338 \mathrm{mg} / \mathrm{kg}$ are threshold. The Inspector Quadro Tabs does not possess embryotoxic and teratogenic properties, does not cause changes in linear measurements and fetal weight, the number of fetuses in the litter, or anatomical disorders and skeletal ossification.

\section{DECLARATIONS}

\section{Authors' Contribution}

Irina A. Stepanova planned this investigation, took part in its development and controlled the experimentation, drafted the manuscript. Gulnara B. Arisova carried out all the preparations for the experiment, made manipulation with laboratory animals, Mikhail V. Arisov observed and monitored the state of animals, did an autopsy of fallen animals, calculated and interpreted the results. Irina A. Stepanova examined the acute and subchronic toxicity of the drug; Mikhail V. Arisov and Gulnara B. Arisova carried out the investigation of embryotoxic properties. All authors read and approved the final manuscript.

\section{Competing interests}

Authors state no conflict of interest.

\section{Acknowledgements}

The present investigation has been financially encouraged by Closed joint-stock company "Scientific-production firm "Ekoprom".

\section{Consent to publish}

All the authors approved and agreed to publish the manuscript

\section{REFERENCES}

Arisov MV and Smirnova ES (2016). Pharmacotoxicological determination of the new complex drug "Gelmintal" (tablets) based on moxidectin and praziquantel. Veterinary, zootechnics and biotechnology, 6: 84-89. Available at: https://www.elibrary.ru/item.asp?id=26210917

Burkov PV (2013). Study of the embryotoxic and teratogenic properties of the "Heprima for swine". Newsletter of the Orenburg State Agrarian University, 3 (41): 119-121. Available at: https://cyberleninka.ru/article/n/izuchenie-embriotoksicheskih-iteratogennyh-svoystv-geprima-dlya-sviney/viewer

Dyban AP, Puchkov VF and Chebotar NA (1986). Guidance on studying embryotoxic activity of pharmaceutical substances and their effect on fertility. Moscow, p. 36. 
Elhawary NM, Sorour SSGh, Bazh EK, El-Abasy MA, El-Madawy MA, Abdel Aziz AR, Sultan K and Omar MA (2018). Toxicity of fipronil in rabbits as a therapeutic drug for "Psoroptes cuniculi": A preliminary observation. Journal of Experimental and Applied Animal Sciences, 2 (3): 260-265. DOI: https://doi.org/10.20454/jeaas.2018.1399

Lutfullin MKh, Lutfullin NA and Shangaraev RI (2017). Study of the embryotoxic properties of the NB compound. Veterinary, zootechnics and bitotechnology, 7: 76-81. Available at: https://www.elibrary.ru/item.asp?id=29924052

Lutfullin MKh, Shangaraev RI, Galyautdinova RR and Terentyeva ZKh (2018). The results of the study of acute and chronic toxicity of antiparasitic NB compounds. Newsletter of the Orenburg State Agrarian University, 6 (74): 145-147. Available at: https://www.elibrary.ru/item.asp?id=36716444

Mironov AN (2012) Guidelines for conducting preclinical studies of drugs. Part one. Moscow, p. 944.

Nazarova AA, Polishchuk SD, Stepanova IA, Churilov GI and Nguyen HC (2014). Biosafety of the application of biogenic nanometal powders in husbandry. Journal of Advances in Natural Sciences: Nanoscience and Nanotechnology, 1(5): 1-6. DOI: https://DOI:10.1088/2043-6262/5/1/0150139

Polishchuk SD, Nazarova AA and Stepanova IA (2015). Toxicological characterization of bio-active drugs on basis of Iron Fe, Co, and Copper $\mathrm{Cu}$ nanopowders. IOP Conference Series: Materials Science and Engineering, 98 (2015) 012037: 1-8. DOI: https://doi:10.1088/1757-899X/98/1/012037

Safiullin RT (2006). Avermectins in the Russian veterinary market. Russian veterinary journal. Farm animals, 2: 6-8. Available at: https://www.elibrary.ru/item.asp?id=16554363

See AM, McGill SE, Raisis AL and Swindells KL (2009). Toxicity in three dogs from accidental oral administration of a topical endectocide containing moxidectin and imidacloprid. Australian Veterinary Journal, 87 (8): 334-337. DOI: https://doi.org/10.1111/j.1751-0813.2009.00448.x

Stepanova IA and Koshkarev EA (2019). Determination of allergenic properties of the complex drug "Inspector Quadro Tabs". Collection of scientific articles on the materials of the international scientific conference. May 15-17, Moscow / resp. ed. E.N. Indyuhova. - M ., All-Russian Research Institute of Fundamental and Applied Parasitology of Animals and Plants, a branch of the Federal State Budgetary Scientific Institution, Federal Research Center - All-Russian Scientific Research Institute of Experimental Veterinary Medicine of Russian Academy of Science, p. 758. DOI: https://DOI: 10.31016/978-5-9902340-8$\underline{6.2019 .20 .600-605}$

Sun Q, Mao R, Wang D, Hu Ch, Zheng Y and Sun D (2016). The cytotoxicity study of praziquantel enantiomers. Drug Design, Development and Therapy, 10: 2061-2068. DOI: https://doi:10.2147/DDDT.S98096

Tamparon RJC, Bayotas SC, Cuadra BES, Camama C and Abrenica-Adamat LR (2015). Dose-dependent effects of Abamectin in acute embryotoxicity and morphological defects of sea urchin (Strongylocentrotus sp.) gametes. AACL Bioflux, 8 (4): 573 -578.

Tang KN, O’Connor MR, Landolfi J and Van Bonn W (2019). Safety and efficacy of milbemycin oxime and lufenuron to treat Argulus spp. infestation in smooth back River Stingrays (Potamotrygon orbignyi) and Magdalenae River Stingrays (Potamotrygon Magdalenae). Journal of Zoo and Wildlife Medicine, 50 (2): 383-388. DOI: https://doi.org/10.1638/2018-0162

Zuskova E, Piackova V, Machova J, Chupani L, Steinbach C, Stara A and Velisek J (2018). Efficacy and toxicity of praziquantel in helminth-infected barbel (Barbus barbus L.). Journal of Fish diseases, 41(4): 643-649. DOI: https://doi.org/10.1111/jfd.12764 